\title{
OBSERVATORIO METROPOLITANO \\ LA CRISIS QUE VIENE. ALGUNAS NOTAS PARA AFRONTAR ESTA DÉCADA (MADRID: TRAFICANTES DE SUEÑOS, 2011)
}

\begin{abstract}
Antonio Alaminos Fernández
Estudiante de la Licenciatura de Publicidad y Relaciones Públicas en la Universidad de Alicante, España
\end{abstract}

Recibido: 15/05/2012

Aceptado: 31/05/2012

Observatorio Metropolitano (2011). La crisis que viene. Algunas notas para afrontar esta década. Madrid: Traficantes de Sueños, 130 páginas

El libro La crisis que viene, publicado en marzo del 2011 por la editorial Traficantes de Sueños, aparece bajo la firma colectiva del denominado "Observatorio Metropolitano". Esta obra es el resultado de la colaboración establecida entre un equipo interdisciplinar de investigadores. Exponen una labor híbrida, donde la investigación, la reflexión crítica se combina con la voluntad de intervención política. Es algo que se aprecia continuamente a lo largo del libro. Su carácter interdisciplinar se aprecia claramente en el resultado, en la medida que considera la crisis desde múltiples perspectivas y no solamente desde el ámbito de la economía. Presenta, en ese sentido, una visión bastante panorámica donde se consideran tanto las condiciones económicas y políticas que han generado la crisis, el modo en que los medios de comunicación y los grupos que defienden el statu quo la justifican, así como sus repercusiones sociales y sobre el diseño del estado de bienestar. Para ello emplea una visión crítica que denuncia la manipulación y tergiversación de la realidad de la crisis actual. Pero también se aprecia una voluntad de intervenir en la realidad, mediante recomendaciones y propuestas que puedan ofrecer vías alternativas para mejorar y transformar la realidad actual. 
Es un libro que aspira, y lo logra en gran parte, a mostrar con claridad y sencillez los elementos clave necesarios para comprender lo que está sucediendo en la actualidad. Representa con ello un complemento importante para la lectura de las noticias del día a día, dado que permite valorar el sentido de las argumentaciones que ofrecen los políticos. A qué visión y lectura del mundo tan sesgada y particular corresponde. Es evidente que no existe una única interpretación de lo que está sucediendo, las consecuencias de ello o las vías adecuadas para salir de la crisis. La perspectiva que utilizan los gobiernos es claramente una perspectiva específica, que favorece a unos intereses concretos, que no siempre son identificables con el interés general.

Cabe destacar en este trabajo su capacidad divulgativa. Es un libro que pretende llegar a un público medio, no especialista. Que quiere explicar de la mejor forma y del modo más accesible. Es algo que se aprecia ya desde el principio, con una simple ojeada al índice. El índice es en sí mismo, un esquema y un resumen sintético del plan de la obra. De sus propuestas y, en parte, de sus conclusiones más destacables. Está estructurado en una introducción, tres capítulos y un epílogo. La secuencia, especialmente la que contienen los tres capítulos, nos refiere a tres momentos concretos. Primero las razones que se utilizan para legitimar y justificar la crisis y las actuaciones que se están llevando a cabo desde la política. En el segundo, la noción de crisis se amplía, mucho más allá de lo económico; se incorpora el significado real de la crisis en términos de polarización social, desmantelamiento del estado de bienestar o crisis medio ambientales. En tercer lugar, se exponen las consecuencias que está teniendo la crisis en las sociedades desarrolladas, incorporando una reflexión sobre la necesidad de actuar desde la sociedad misma. El epílogo es una llamada a la acción y la reflexión. En conjunto, como decíamos, es un libro escrito para llegar al mayor número de lectores. El modo de difusión empleado, mediante licencia Creative Commons, permite el acceso libre y gratuito de todos los públicos. Es, en todos los sentidos, un libro que busca ser leído, ofreciendo para ello todas las facilidades posibles.

Vamos seguidamente a detallar las ideas que enfatiza la obra, siguiendo para ello la estructura misma del libro. La Introducción presenta una exposición sobre la situación que lleva a la necesidad de escribirlo. Como los poderes financieros, apoyándose siempre en decisiones tomadas por los políticos que les favorecen, han dirigido y dirigen la economía internacional hacia donde mayor beneficio a corto plazo puedan lograr. Destacan como la meta que persiguen los poderes financieros son completamente cortoplacistas, del beneficio inmediato. Esta perspectiva abandona a su suerte a las sociedades y se despreocupa de la estabilidad social y del estado de bienestar que la garantiza. Llegan 
a indicar la siguiente etapa en la estrategia financiera, donde tras el acoso y especulación contra las deudas públicas, la previsión es el incremento de los intereses como consecuencia de la especulación en los mercados de materias primas y petróleo. Sirve la introducción para posicionar al lector en los mecanismos generales y algunos de los actores principales, desde los políticos, los poderes financieros internacionales y sobre todo las sociedades. Estas últimas inmersas en una situación cada vez más caótica y empobrecida, como consecuencia del desmantelamiento del estado de bienestar.

En el primer capítulo Cinco formas de no entender nada... o de justificar a aquellos que más provecho obtienen de la crisis. Se inicia con una descripción del proceso que desarrolla la crisis, desde el momento que se atribuye exclusivamente al mundo financiero internacional, pasando por su expresión posterior en la crisis de la burbuja inmobiliaria para continuar con el acoso a las deudas públicas. Tras relatar la secuencia de lo sucedido, pasa a exponer las excusas adoptadas y que se emplearan para justificar los recortes sociales actuales. Comienza, en su primera parte con la afirmación La economía obedece a leyes propias. Las políticas económicas deben ser diseñadas según estas reglas. En un procedimiento que emplearán sistemáticamente, utilizan la frase como objeto de la reflexión y crítica posterior. En esta parte debaten cómo la economía reduce la realidad simplificándola y falsificándola hasta el punto de que sus supuestas leyes son una aberración, que sitúa las formas de producir y distribuir la riqueza en un lugar de intercambio desigual, el capitalismo. Seguidamente, va mostrando los axiomas que se intentan imponer.

En la segunda parte, Si los escenarios no obtienen suficientes beneficios no se genera empleo. Lo prioritario es generar un escenario propicio para que haya inversión y, por lo tanto, empleo, expone que se postula una relación que en la realidad no se cumple. Los beneficios no se invierten nuevamente en la economía productiva. Es más que evidente que los beneficios se están refugiando en actividades especulativas financieras que reportan unos beneficios mayores. Pero no crean empleo ni mejoras en las capacidades productivas. Tras un recorrido histórico, mostrando el proceso experimentado por los beneficios en occidente, concluye que aparece una especie de rentista financiero no productivo. En ese sentido, la actuación más coherente debe asegurar la inversión productiva y no solamente la garantía de beneficios. En la tercera parte El empleo es demasiado caro. Hemos vivido por encima de nuestras posibilidades: Ahora hay que ajustarse el cinturón para que la economía se recupere, explica la forma en la productividad, los salarios y el consumo aparecían ligados en el sistema económico. En ese sentido, la producción de riqueza mediante burbujas (como las del ladrillo) no reflejan una realidad de una mano de obra con salarios 
en contracción y con contratos de temporalidad creciente. La noción misma de empleo, en la forma en que se concreta, se aleja bastante de la imagen de exceso que se pretende vender. En la cuarta parte El gasto social supone una carga creciente que la economía ya no puede soportar. O también: hay que transmitir confianza a los mercados y reducir lo antes posible el déficit público, explica cómo la idea de que el estado de bienestar lo mantienen los empresarios, detrayendo recursos de la inversión es una falacia. En España, dicen los autores, aproximadamente el $75 \%$ del estado de bienestar se mantiene por los asalariados, mediante el IRPF. O indirectamente desde impuestos como el IVA. La crisis de liquidez consecuencia del estallido de la burbuja, ha sido aprovechada por los poderes financieros para especular contra las deudas públicas, refinanciando de ese modo sus propios déficits. Para finalizar el primer capítulo, en su quinta parte, La crisis acabará, Volveremos a crecer. Debate y contradice la presunción de que volver a crecer es algo inevitable y que es el futuro más seguro. Especialmente en el caso español, acostumbrados a un crecimiento rápido. Sin embargo, esto no es así, y las dudas sobre el alcance de la crisis son profundas. Especialmente con las respuestas dadas hasta la actualidad. Como de síntesis de este primer capítulo se afirma que "de momento al menos, la clausura de toda oportunidad para el reformismo y la pobre imaginación de la crítica nos devuelven a un paisaje social caracterizado por la presión sobre los sectores más vulnerables, la destrucción de toda autonomía social respecto de las lógicas de la financiación y, lo que es peor, una clara y nítida pendiente de involución política".

En el segundo capítulo del libro, Cuando se dice crisis se debería decir..., encontramos tres partes que detallan y extienden la noción de crisis. En El fin del espejismo de la clase media explica que "durante la larga década que se extiende de mediados de los años noventa hasta los dos mil... la población española, disfrutó de un placentero sueño de prosperidad" que finalizo en la crisis actual a la cual llegó gente favorecida y otra no. Del sueño se despertó debido a la crisis del ladrillo y las especulaciones de la vivienda. En la segunda parte, Los derecho sociales en situación terminal, explica el dilema que tienen los estados respecto a qué hacer con las deudas y de dónde conseguir el dinero. Esto repercute en un recorte de los derechos sociales y en la reducción en gastos públicos. Se expone con abundancia de datos de cómo se podrían haber evitado y contrarrestado este tipo de reducciones. Para finalizar la tercera y última parte, La ecología de la crisis: la destrucción del medio ambiente, habla de que la ecología y la protección del medio ambiente se ve afectada profundamente por la crisis actual debido a que la gente prefiere llegar a fin de mes y no le importa llegar al final del siglo. Las consecuencias para el medio plazo son notables. 
El último capítulo del libro, La crisis que viene, se ocupa de intentar abrir opciones al bloqueo que puede suponer la acción de mercados internacionales o la complejidad de la crisis. Destacan sobre todo, la necesidad de no creer que el sistema se autorregulará y que la solución de la crisis la darán los mismos que la han creado. Plantea la necesidad de la acción y la movilización, si realmente se desea intentar salir de la crisis. Se da por hecho que existirá conflicto. Este es casi inevitable según la dinámica de los procesos económicos e institucionales en marcha. La crisis no es solo económica o social. Es y será sobre todo, una crisis política. En palabras de los autores, "todos ellos apuntan a una sociedad en crisis y a una situación política sumergida en una decadencia prácticamente irreversible: la «guerra entre pobres» como forma de gobierno, la competencia entre territorios como forma demando sobre la crisis, el miedo como tonalidad afectiva dominante, la involución europea -por momentos al borde de su desintegración-, la falta de una contraparte capitalista capaz de apostar por su propia reforma y por último la crisis de la democracia y de los mecanismos de representación que hasta la fecha han sostenido los consensos institucionales más básicos".

Este capítulo está estructurado en siete partes.

La primera parte del tercer capítulo trata de La "guerra entre pobres". En ella destaca la fractura social que se produce entre empleados y desempleados, entre inmigrantes y no inmigrantes, etcétera. En definitiva, que las tensiones y conflictos se resuelvan entre grupos sociales y no contra el poder financiero. En la segunda parte, Competencia de territorios plantea como los enfrentamientos pueden articularse, no sólo desde la fractura social, si no también articulados en ideologías de carácter nacionalista, regionalista o localista, reproduciendo la lógica del conflicto interno en la sociedad. El siguiente punto es El miedo y el gobierno de las pasiones, donde nos habla del "miedo e impotencia, miedo y resignación, miedo y resentimiento. Pero siempre miedo."Propone una que debemos intentar evitar la implantación del miedo que paraliza la reacción ante la ofensiva de los poderes financieros. La cuarta parte, El cierre del reformismo y el problema de Europa, habla del problema económico localizado en los países europeos y cómo las vías de salida pasan por una mayor democratización de Europa y un "control de los flujos financieros". En su quinta parte La crisis de la representación, debate la sensación de impotencia de los individuos para cambiar las cosas. Como sintetiza en la frase "Las grandes mayorías sociales, aisladas, atomizadas, fuertemente despolitizadas, carecen de espacios de discusión y autoorganización". El sistema político y el bipartidismo PP-PSOE en España, no facilita que la política cambie sus respuestas a la crisis social. En la siguiente parte La izquierda en ruinas o el fin de la 
socialdemocracia y Las tareas inmediatas explica el porqué y cómo la izquierda está en decadencia por una mala gestión política en Europa Occidental. Identifica las tareas principales para generar empleo, disminuir el número de parados y reducir el déficit público. Para ello propone "La organización a escala continental de una fiscalidad sobre la circulación financiera y las rentas de capital, la creación de un presupuesto común y la organización de una Renta Básica universal". En definitiva, un programa de izquierdas alternativo para responder a la crisis y los poderes que se benefician de ella.

Para finalizar A modo de epílogo: a por el gran reparto destaca las ideas motrices del libro. La crisis y su desarrollo no es consecuencia de leyes inevitables sino de acciones y dejaciones del poder político, de los gobiernos. La crisis actual sólo "está determinada, de principio a fin, por decisiones políticas". Por ello, cabe reaccionar y actuar en defensa de los intereses de la sociedad democrática y del estado de bienestar.

Se trata de un libro claramente divulgativo. Pretende, y en cierto modo lo consigue, explicar a los ciudadanos las claves de la crisis que están viviendo. Esta intención de proximidad se aprecia en la forma de titular y estructurar el libro donde sólo con leer el nombre del capítulo se sabe de qué trata. En definitiva, un perfecto manual para entender la crisis, sus causas, y sus posibles consecuencias. Destacar que no es un libro que se limite a analizar y explicar la crisis. Los autores proponen soluciones alternativas a las que ya están siendo adoptadas por los gobiernos europeos. Y llaman a la acción social. 